\title{
The Fh8 tag: A fusion partner for simple and cost-effective protein purification in Escherichia coli
}

\author{
Sofia J. Costa ${ }^{\mathrm{a}, \mathrm{b}, 1}$, Eduardo Coelho ${ }^{\mathrm{a}, \mathrm{b}, 1}$, Lara Franco ${ }^{\mathrm{a}, \mathrm{b}}$, André Almeida ${ }^{\mathrm{c}, \mathrm{d}}$, António Castro ${ }^{\mathrm{b}}$, \\ Lucília Domingues ${ }^{\mathrm{a}, *}$ \\ a IBB - Institute for Biotechnology and Bioengineering, Centre of Biological Engineering, Universidade do Minho, Campus de Gualtar, 4710-057 Braga, Portugal \\ ${ }^{\mathrm{b}}$ Instituto Nacional de Saúde Dr. Ricardo Jorge (INSARJ), Porto, Portugal \\ ${ }^{\mathrm{c}}$ Hitag Biotechnology Lda., Biocant-Parque Tecnológico de Cantanhede, Portugal \\ ${ }^{\mathrm{d}}$ Instituto de Ciências e Tecnologias Agrárias e Agro-Alimentares (ICETA), Universidade do Porto, Porto, Portugal
}

\section{A R T I C L E I N F O}

\section{Article history:}

Received 19 July 2013

and in revised form 9 September 2013

Available online 29 September 2013

\section{Keywords:}

Fh8 tag

Affinity tag

Calcium binding protein

Hydrophobic interaction chromatography

Escherichia coli

\begin{abstract}
A B S T R A C T
Downstream processing is still a major bottleneck in recombinant protein production representing most of its costs. Hence, there is a continuing demand of novel and cost-effective purification processes aiming at the recovery of pure and active target protein. In this work, a novel purification methodology is presented, using the Fh8 solubility enhancer tag as fusion handle. The binding properties of Fh8 tag to a hydrophobic matrix were first studied via hydrophobic interaction chromatography (HIC). The Fh8 tag was then evaluated as a purification handle by its fusion to green fluorescent protein and superoxide dismutase. The purification efficiency of the Fh8-HIC strategy was compared to the immobilized metal ion affinity chromatography (IMAC) using the $\mathrm{His}_{6}$ tag. Results showed that the Fh8-HIC binding mechanism is calcium-dependent in a low salt medium, making the purification process highly selective. Both target proteins were biologically active, even when fused to Fh8, and were successfully purified by HIC, achieving efficiencies identical to those of IMAC. Thus, the Fh8 acts as an effective affinity tag that, together with its previously reported solubility enhancer capability, allows for the design of inexpensive and successful recombinant protein production processes in Escherichia coli.
\end{abstract}

(c) 2013 Published by Elsevier Inc.

\section{Introduction}

The continuing growth of biotechnology industry demands new strategies for the rapid and economical recombinant protein production through the use of a variety of host organisms and solubility as well as affinity partners [1-5]. The purification of a protein of interest from biological mixtures using rapid, robust and cost-effective methodologies is still a current challenge for academia and industry. Taking into account that the downstream processing comprises up to $80 \%$ of the production costs [2], novel solutions that simplify the protein purification process are essential for the biotechnology's progress. This purification bottleneck has been fairly overcome by the use of affinity fusion partners together with DNA recombinant techniques that allow to clone in frame the peptide or protein affinity tag at the $\mathrm{N}$ - or C-terminus end of the target construct [2]. These fusion partners or tags diverge in molecular size and complexity, and can also be used to improve soluble protein production besides facilitating its purification by specific interaction with a known ligand/adsorption ma-

\footnotetext{
* Corresponding author.

E-mail address: luciliad@deb.uminho.pt (L. Domingues).

1 These authors contributed equally to this work.
}

trix [3]. Several affinity tags are commercially available for research or large scale protein production as, for instance, the Glutathione S-Transferase (GST) ${ }^{2}$ tag [6], Maltose Binding Protein (MBP) tag [7] and Hexahistidine tag [8] that have affinity to bind immobilized glutathione, maltose and nickel, respectively. Although being widely used, these fusion tags often yield low levels of protein purity due to unspecific and/or weak interactions with the corresponding matrices [9]. New purification tags are constantly emerging, outperforming the existing techniques and advancing the affinity concept or protein detection, as for instance, the Sitag [10], Tamavidin tag [11], Tab2 tag [12], intein-mediated purifications [13], Heme tag [14], Z-basic tag [15], Dock tag [16] and the HiCaM tag [17]. The ideal purification process should: allow efficient and high yield protein recovery from a biological mixture; be universally applied to any protein without disturbing its function; use a small fusion partner; be compatible with native

\footnotetext{
${ }^{2}$ Abbreviations used: GST, glutathione S-transferase; MBP, maltose binding protein; Trx, thioredoxin; NusA, N-utilization substance A; GFP, green fluorescent protein; SOD, superoxide dismutase; TEV, tobacco etch virus; MCS, multiple cloning site; HIC, hydrophobic interaction chromatography; IMAC, immobilized metal ion affinity chromatography; SDS-PAGE, sodium dodecyl sulfate-polyacrylamide gel electrophoresis.
} 
conditions; and it should offer great control of selectivity (binding and elution of the protein of interest) while using inexpensive and high capacity resins $[5,18]$.

In a previous work [21] we have shown that the Fh8 peptide could be used as a solubility enhancer partner, improving protein expression and solubility as the well-known Thioredoxin (Trx), N-utilization substance A (NusA) or MBP fusion partners. Moreover, we have also shown that small fusion tags allowed an easier evaluation of the target protein solubility. Thus, when compared to larger fusion tags, the Fh8 tag was considered an advantageous option for soluble protein production in Escherichia coli due to its low molecular weight and its efficient solubility enhancing effect.

In this work, we investigate the Fh8 solubility enhancer tag as a novel fusion purification handle by combining the calcium binding intrinsic property of the Fh8 molecule with an inexpensive hydrophobic resin (phenyl-Sepharose). The Fh8 (GenBank accession No. AF213970) was first isolated from the excreted/secreted proteins of the Fasciola hepatica parasite and recombinantly produced in $E$. coli for diagnostic purposes, presenting a molecular weight of $8 \mathrm{kDa}$ [19]. This recombinant protein was previously characterized as a calcium sensor protein that changes its structure upon calcium binding, exposing its hydrophobic residues to interact with its targets or other molecules [20]. We demonstrate here that the solubility enhancer Fh8 tag [21] interacts with the phenyl-Sepharose hydrophobic resin with an identical mechanism as other calcium-binding proteins $[22,23]$. Furthermore, using the green fluorescent protein (GFP) and the superoxide dismutase (SOD) as target model proteins, we also reveal that the Fh8 tag can be successfully applied as a purification handle for simple, rapid, and low cost recovery of biologically active proteins. By acting simultaneously as a solubility enhancer tag [21] and purification handle at the same time, the Fh8 offers an efficient and economical recombinant protein production in $E$. coli.

\section{Materials and methods}

\section{Cloning of sod and gfp genes into expression vectors}

Both gfp and sod genes were first modified and amplified by PCR to be later sub-cloned into the pETM11 (EMBL) and pETMFh8 [21] expression vectors. Both vectors present a $\mathrm{N}$-terminal $\mathrm{His}_{6}$ tag followed by a recognition site for the Tobacco Etch Virus (TEV) protease and the Multiple Cloning Site (MCS). In the case of pETMFh8, the Fh8 tag is located between the $\mathrm{His}_{6}$ tag and the TEV recognition site [21].

The PCRs were conducted using minipreps (GenElute ${ }^{\mathrm{TM}}$ Plasmid Miniprep Kit - Sigma) of gfp and sod harboring plasmids as templates and the Phusion High-Fidelity DNA Polymerase (New England Biolabs - NEB), according to the manufacturer's instructions. Specific primers were designed as follows: Forward primer: 5'-TCTATTCCATGGGATCC $+18 \mathrm{nt} \mathrm{gfp} / \mathrm{sod}-3^{\prime}$ and Reverse primer: 5'-AATAGACTCGAGTTA + $21 \mathrm{nt} \mathrm{gfp} / \mathrm{sod}^{-3} \mathrm{3}^{\prime}$, to introduce the NcoI/ BamHI restriction sites (underlined) at the N-terminal of both genes and the XhoI restriction site (underlined) after the stop codon (bold) at the C-terminal of both genes. After DNA purification (QIAquick DNA gel extraction kit - Qiagen), the PCR products and the expression vectors were digested using the NcoI and XhoI restriction enzymes (New England Biolabs) and DNA ligations were carried out using the Rapid DNA Ligation kit (Roche).

E. coli TOP10 competent cells were transformed with the obtained vectors and the resulting clones were verified by colony PCR using the T7 forward and reverse universal primers. The correct insertion of $g f p$ and sod genes into the pETM11 and pETMFh8 expression vectors was additionally confirmed by sequencing with both T7 forward and reverse universal primers.
Expression of Fh8 tag, HisGFP/SOD and Fh8GFP/SOD fusion proteins in E. coli

The expression strains and induction conditions used in this work were selected from a small-scale screening using $10 \mathrm{~mL}$ cultures (see Supplementary file 1). GFP recombinant proteins and the Fh8 tag were expressed in 2 L cultures using the E. coli BL21 Codon Plus-RIL strain. SOD recombinant proteins were expressed in $2 \mathrm{~L}$ cultures of $E$. coli Rosetta strain. Recombinant proteins were expressed as follows: pre-cultures were grown overnight $(\mathrm{o} / \mathrm{n})$ at $37{ }^{\circ} \mathrm{C}$ and a dilution factor of 50 was used for inoculation of all cultures. Cells in a total culture volume of $2 \mathrm{~L}$ (eight 1-L flasks of $250 \mathrm{~mL}$ of culture media) were grown at $37{ }^{\circ} \mathrm{C}$ and $200 \mathrm{rpm}$ to a final O.D $D_{600 \mathrm{~nm}}$ of 0.4-0.6. E. coli cultures were induced with isopropyl- $\beta$-D-1-thiogalactopyranoside (IPTG) at $0.2 \mathrm{mM}, 18^{\circ} \mathrm{C}$, o/n (for SOD and GFP expressions) or at $1 \mathrm{mM}, 30^{\circ} \mathrm{C}, 4 \mathrm{~h}$ (for Fh 8 tag expression). After induction, three $5 \mathrm{~mL}$ samples were taken from each culture for dry weight estimation and the remaining cells were harvested for $25 \mathrm{~min}$, at $4{ }^{\circ} \mathrm{C}$ and $4000 \mathrm{rpm}$. Cell pellets were washed once with phosphate buffer saline $1 \times($ PBS $1 \times)$ and collected again by centrifugation. Bacterial pellets were then stored at $-20^{\circ} \mathrm{C}$.

Stock solutions of antibiotics for plasmid maintenance and protein expression were prepared, filtered through $0.2 \mu \mathrm{m}$ and stored at $-20^{\circ} \mathrm{C}$ to be used in culture media with the following concentrations: kanamycin $50 \mu \mathrm{g} \mathrm{mL} \mathrm{L}^{-1}$ and chloramphenicol $10 \mu \mathrm{g} \mathrm{mL}^{-1}$.

\section{Fh8 purification by HIC}

Three different HIC purifications were tested to evaluate the interaction of Fh8 with the hydrophobic resin in the presence and absence of calcium, following the strategy presented in Supplementary file 2. Cell pellets of $1.5 \mathrm{~L}$ culture of the Fh8 tag were thawed and resuspended in a total volume of $3 \times 25 \mathrm{~mL}$ of lysis buffer (50 mM Tris $\mathrm{pH} 7.6$ and $150 \mathrm{mM} \mathrm{NaCl}$, supplemented with $1 \times$ complete free EDTA protease inhibitor (Roche), $5 \mu \mathrm{g} \mathrm{mL}^{-1}$ DNAse (Sigma) and $1 \mathrm{mg} \mathrm{mL}^{-1}$ lysozyme (Sigma)). The lysis buffer was also supplemented with $5 \mathrm{mM} \mathrm{CaCl}_{2}$, accordingly. After resuspension, cells were incubated at room temperature for $10 \mathrm{~min}$ and then lysed by sonication (Branson) for six cycles of $30 \mathrm{~s}$ each, with $30 \mathrm{~s}$ intervals. Aliquots of $100 \mu \mathrm{L}$ of total lysates were taken and stored at $4{ }^{\circ} \mathrm{C}$. Supernatant fractions were collected from the insoluble debris by centrifugation at $10,000 \mathrm{rpm}, 30 \mathrm{~min}, 4^{\circ} \mathrm{C}$ and aliquots of $100 \mu \mathrm{L}$ were stored at $4{ }^{\circ} \mathrm{C}$ for Bradford estimation of the total protein content and for sodium dodecyl sulfate-polyacrylamide gel electrophoresis (SDS-PAGE) analysis. The Fh8 tag purifications were conducted in the Biologic Duoflow FPLC system (Bio Rad) using a $5 \mathrm{~mL}$ pre-packed Phenyl Sepharose 6 Fast Flow High Sub column (GE Healthcare). Supernatant samples were loaded onto the HIC column, using the following buffers: in the HIC-1, the Fh8 tag was purified by HIC using a Tris- $\mathrm{NaCl}$ buffer without calcium addition ( $50 \mathrm{mM}$ Tris $\mathrm{pH} 7.6$ and $150 \mathrm{mM} \mathrm{NaCl}$ ). In the HIC-2, the Fh8 tag was purified by HIC using the Tris-NaCl buffer supplemented with $5 \mathrm{mM} \mathrm{CaCl}_{2}$. For both purifications, the elution buffer was used in the same concentration as indicated in Table 1. In the HIC-3, the Fh 8 tag was purified by HIC using the Tris- $\mathrm{NaCl}$ buffer supplemented with $5 \mathrm{mM} \mathrm{CaCl} 2$ but with two different elution buffers: a first elution buffer with EDTA (50 mM Tris $\mathrm{pH} 7.6,150 \mathrm{mM} \mathrm{NaCl}$ and $5 \mathrm{mM}$ EDTA) and a second elution buffer identical to the described at Table 1 (50 mM Tris pH 10). Aliquots of all supernatant and flow-through samples, washing steps and eluted samples were stored at $4{ }^{\circ} \mathrm{C}$ to be further analyzed. 
Table 1

Composition of purification buffers.

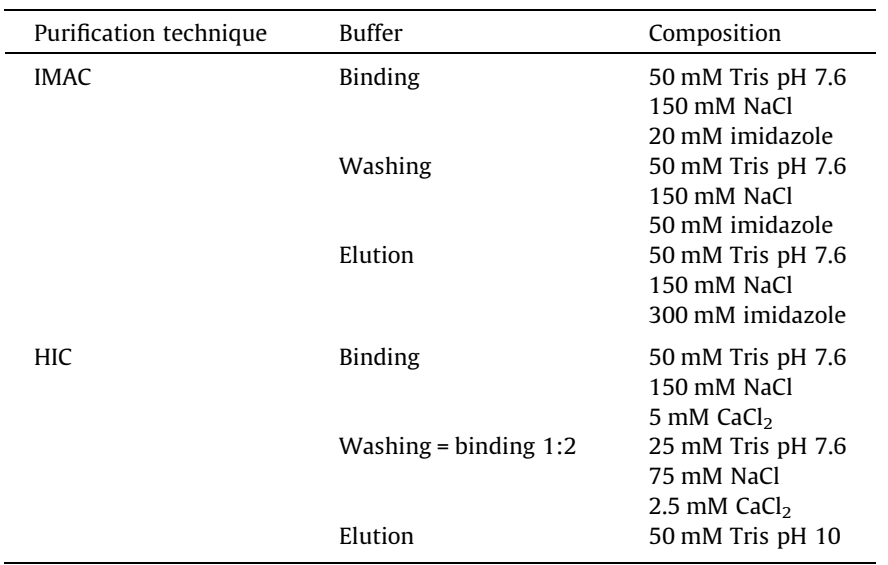

Protein purification by HIC and by IMAC

Cell pellets of HisSOD, Fh8SOD, HisGFP and Fh8GFP proteins (one pellet per protein, corresponding to $1 \mathrm{~L} \mathrm{E}$. coli culture) were thawed and resuspended in a total volume of $2 \times 20 \mathrm{~mL}$ of lysis buffer ( $50 \mathrm{mM}$ Tris pH 7.6 and $150 \mathrm{mM} \mathrm{NaCl}$, supplemented with $1 \times$ complete free EDTA protease inhibitor (Roche), $5 \mu \mathrm{g} \mathrm{mL}^{-1}$ DNAse (Sigma) and $1 \mathrm{mg} \mathrm{mL}^{-1}$ lysozyme (Sigma)) with the addition of $20 \mathrm{mM}$ imidazole, for IMAC purifications $(1 \times 20 \mathrm{~mL})$, or $5 \mathrm{mM} \mathrm{CaCl}_{2}$, for HIC purifications $(1 \times 20 \mathrm{~mL})$. Cells were lysed as previously mentioned in the Fh8's purification and aliquots of total lysates and supernatant samples were stored at $4{ }^{\circ} \mathrm{C}$ for Bradford estimation of the total protein content and for SDS-PAGE analysis. SOD and GFP target proteins were purified in parallel by HIC, using the same column as for the Fh8's purification, and by IMAC, using a $5 \mathrm{~mL}$ Histrap pre-packed column (GE Healthcare). All the proteins were purified following an identical strategy (see Supplementary file 2). The composition of specific buffers used for each purification methodology is described in Table 1 . The obtained purified SOD and GFP fusion proteins were dialyzed in $50 \mathrm{mM}$ Tris $\mathrm{pH}$ 7.6, $150 \mathrm{mM} \mathrm{NaCl}$ buffer, filtered through $0.2 \mu \mathrm{m}$ and stored at $4{ }^{\circ} \mathrm{C}$ and $-20^{\circ} \mathrm{C}$ until used. Columns regeneration and storage was performed according to the manufacturer's instructions.

\section{Dual protein purification using HIC/IMAC and IMAC/HIC}

Fh8GFP and Fh8SOD fusion proteins were purified by HIC followed by IMAC using the same above-mentioned protocols, with the following modifications: after HIC purification, eluted samples were dialyzed in $50 \mathrm{mM}$ Tris $\mathrm{pH}$ 7.6, $150 \mathrm{mM} \mathrm{NaCl}$ buffer supplemented with $20 \mathrm{mM}$ imidazole. The IMAC/HIC purification was only conducted for the Fh8SOD protein. Eluted samples from the IMAC purification were dialyzed in $50 \mathrm{mM}$ Tris pH 7.6, $150 \mathrm{mM}$ $\mathrm{NaCl}$ buffer supplemented with $5 \mathrm{mM} \mathrm{CaCl}_{2}$, following an identical protocol as above-mentioned. At the end of the HIC/IMAC or IMAC/ HIC purifications, samples were dialyzed in $50 \mathrm{mM}$ Tris $\mathrm{pH} 7.6$, $150 \mathrm{mM} \mathrm{NaCl}$ buffer and stored at $4{ }^{\circ} \mathrm{C}$ and $-20^{\circ} \mathrm{C}$ until needed. Aliquots of all purification samples were stored at $4{ }^{\circ} \mathrm{C}$ to be further analyzed.

\section{Protein electrophoresis and protein quantification}

SDS-PAGE of Fh8 and His fusion proteins was conducted according to the Laemmli method [24] using 12-4\% gels. SDS-PAGE of the Fh8 tag samples was conducted according to the Schagger and Jagow method [25], using 15-4\% gels. Gels were loaded with the PageRuler Unstained Broad Range Protein Ladder (Thermo Scientific). Protein purity and correspondent molecular weights in the SDS-PAGE gels were estimated by densitometry, conducting three independent readings in the Image Lab 2.0 software (Bio Rad), using the Molecular Imager Chemidoc XRS+ system (Bio Rad).

The total protein content of supernatant samples and purification samples was estimated by Bradford method [26], using the Bio Rad protein assay dye reagent and bovine serum albumin as standard. Protein quantifications were also conducted by reading the absorbance of eluted samples at $280 \mathrm{~nm}$. All protein quantifications were conducted in triplicates. Purification efficiencies were estimated by the ratio between the protein amount in eluted samples and the protein amount loaded onto the purification column.

\section{GFP fluorescence measurements and SOD activity evaluation}

The GFP target protein was considered to be active by emitting green fluorescence. The fluorescence intensity of GFP eluted samples was measured in triplicates using a spectrofluorometer with an excitation filter of $475 \mathrm{~nm}$ and an emission filter of $505 \mathrm{~nm}$. The resulting fluorescence intensities were normalized by the protein amount (in milligrams). The SOD activity was evaluated according to the method of Marklund and Marklund [27], in three independent assays, by estimating the inhibition of pyrogallol autoxidation promoted by the eluted samples, using a spectrophotometer at $420 \mathrm{~nm}$.

\section{Results}

\section{The Fh8 tag interaction with the hydrophobic resin}

The Fh8 was expressed in E. coli harboring the pETMFh8 plasmid with an estimated molecular weight of $12 \mathrm{kDa}$ (see Supplementary file 3). Results of the three Fh8's HIC purification protocols (Fig. 1 and Table 2) demonstrated the calcium-dependent interaction of Fh8 with the hydrophobic resin, as follows: in the HIC purification without calcium supplementation in the binding step (HIC-1), most of the loaded Fh8 (gel band of $12 \mathrm{kDa}$ ) was observed in the flow-through (FT lane, gel band of $12 \mathrm{kDa}$ ) and washing (W lane, gel band of $12 \mathrm{kDa}$ ) samples, resulting in a purification efficiency of $0 \%$. The eluted sample (using the $\mathrm{pH} 10$, E lane) did not contain the 12-kDa Fh8's gel band, being majorly composed by two gel bands, one of 23 and other of $54 \mathrm{kDa}$. In the HIC purifications with calcium addition (HIC-2 and HIC-3), the Fh8 was mostly visible in the eluted samples (E lanes, gel band of $12 \mathrm{kDa}$ ) and small leakages were observed in the washing steps. When performing the elution with $50 \mathrm{mM}$ Tris pH 10 (HIC-2), it was possible to observe the Fh8's recovery together with the other two gel bands of 23 and $54 \mathrm{kDa}$. On the other hand, when a first elution step with EDTA supplementation (HIC-3) was performed, only the $12 \mathrm{kDa}$ gel band was observed (lane E1). The other high molecular weight gel bands eluted in $50 \mathrm{mM}$ Tris pH 10 buffer (lane E2). The two elution strategies yielded similar purification efficiencies $(82 \pm 6.2 \%$ and $86 \pm 4.3 \%$, respectively).

These results showed that the Fh8 tag successfully interacted with the HIC resin by using buffers supplemented with calcium.

\section{SOD and GFP purification by HIC and by IMAC}

The Fh8 solubility enhancer tag was evaluated as a purification handle using the HIC in the presence of calcium (purification conditions of HIC-2). Fh8GFP and Fh8SOD recombinant fusion proteins were purified by HIC in parallel with IMAC, and the equivalent 


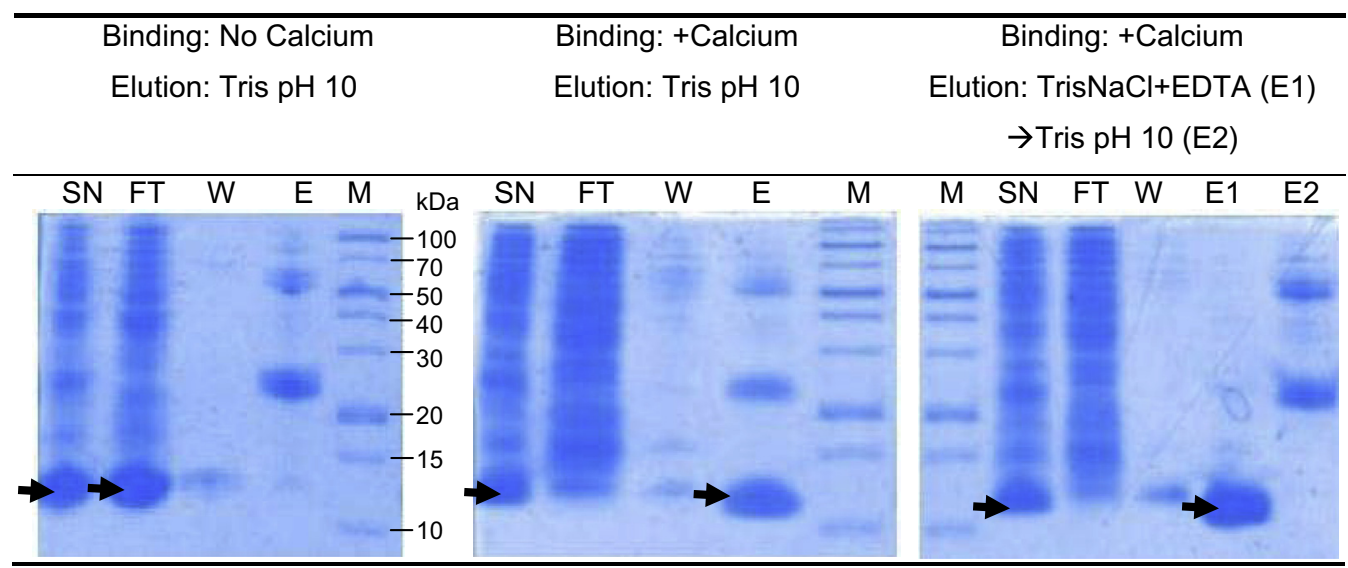

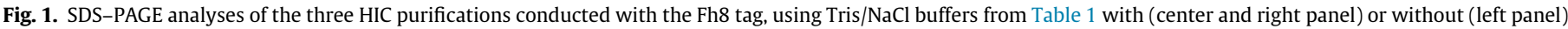

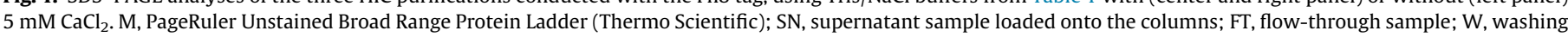

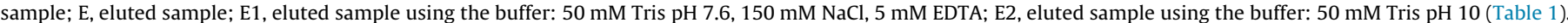
Arrows indicate the Fh8 position in the gel.

Table 2

Fh8 tag purification results using three different HIC protocols.

\begin{tabular}{|c|c|c|c|}
\hline & $\begin{array}{l}\text { HIC-1 } \\
\text { Binding: no calcium } \\
\text { Elution: Tris pH } 10\end{array}$ & $\begin{array}{l}\text { HIC-2 } \\
\text { Binding: }+5 \mathrm{mM} \mathrm{CaCl}_{2} \\
\text { Elution: Tris pH } 10\end{array}$ & $\begin{array}{l}\text { HIC-3 } \\
\text { Binding: }+5 \mathrm{mM} \mathrm{CaCl}_{2} \\
\text { Elution: Tris } \mathrm{NaCl}+\text { EDTA } \rightarrow \text { Tris pH } 10\end{array}$ \\
\hline Loaded $(\mathrm{mg})^{\mathrm{a}}$ & $37 \pm 1.4$ & $22 \pm 0.7$ & $35 \pm 0.9$ \\
\hline Eluted $(\mathrm{mg})^{\mathrm{b}}$ & $0 \pm 0$ & $18 \pm 1.3$ & $31 \pm 1.5$ \\
\hline Purification efficiency $(\%)^{c}$ & $0 \pm 0$ & $82 \pm 6.2$ & $86 \pm 4.3$ \\
\hline
\end{tabular}

His-fused proteins were employed as a reference control for both HIC and IMAC purifications, being also used to evaluate the specific Fh8's hydrophobic interaction of the Fh8 fusion proteins.

The SDS-PAGE comparative analysis (Fig. 2) revealed an identical purification profile between the Fh8-HIC and IMAC methodologies for both Fh8GFP (gel band of $37 \mathrm{kDa}$, Fig. 2a) and Fh8SOD (gel band of $29 \mathrm{kDa}$, Fig. 2c) fusion proteins, with low protein amount in the flow-through (FT lanes) and washing (W lanes) samples, and with most of the protein in the elution samples (E lanes). The eluted samples from HIC and IMAC purifications, however, were not completely pure: the Fh8GFP fusion proteins presented a second gel band (at $22 \mathrm{kDa}$ for HIC and at $28 \mathrm{kDa}$ for IMAC), and the Fh8SOD fusion proteins presented other gel bands of different molecular weights.

The purification efficiencies of Fh8GFP and Fh8SOD were also similar between the Fh8-HIC and IMAC methodologies, as shown in Table 3.

Both HisGFP (gel band of $30 \mathrm{kDa}$, Fig. 2a) and HisSOD (gel band of $21 \mathrm{kDa}$, Fig. 2c) proteins presented an identical purification pattern: they were successfully purified by IMAC but not so well by HIC, in which they were mostly found in the washing samples (W lanes) rather than in the elution samples (E lanes). The HisGFP purification by IMAC yielded a similar efficiency as the Fh8GFP purifications by IMAC or Fh8-HIC (Table 3). In the HIC purification of the HisSOD protein, other gel band from the soluble extract of $E$. coli was observed nearby the HisSOD protein gel band. We could confirm that this gel band did not correspond to the HisSOD protein as it was not purified by IMAC (Fig. 2c, lanes FT and W) and it did not present SOD's biological activity. A protein loss of $96 \pm 8 \%$ was estimated for the HisSOD purification by HIC, taking into account the total protein content and corresponding densitometric analysis in the flow-through and washing samples.

\section{Dual purification system: HIC/IMAC and IMAC/HIC}

Depending on the protein's application, it is often necessary to perform two or more purification steps to increase its purity level. The purity of eluted Fh8GFP and Fh8SOD proteins from the Fh8HIC purification was further evaluated by a second purification with IMAC. A second HIC purification was also conducted with the Fh8SOD protein after IMAC purification. As observed in Fig. $2 b$ and $d$, the HIC/IMAC or IMAC/HIC purifications improved both Fh8GFP and Fh8SOD proteins purity, achieving purity levels between $85 \%$ and $92 \%$ of the target protein, evaluated by densitometric analysis of SDS-PAGE. Moreover, Fh8GFP and Fh8SOD were purified by these dual strategies with similar efficiencies as the single purifications (Table 3): the Fh8GFP yielded a purification efficiency of $98 \pm 7.0 \%$ after HIC/IMAC, and the Fh8SOD achieved a purification efficiency of $70 \pm 28 \%$ or $78 \pm 4.4 \%$ after HIC/IMAC or IMAC/HIC, respectively.

\section{Functional assays of purified fusion proteins}

The Fh8-HIC purification methodology was further compared to the IMAC purification regarding the biological activity of the purified proteins (Fig. 3). In general, the Fh8GFP purified by IMAC resulted in higher relative fluorescence units (RFU) per $\mathrm{mg}$ of protein than the Fh8GFP purified by HIC. The Fh8 tag did not interfere with the GFP fluorescence, and the Fh8GFP protein was, thus, biologically active after being purified by the Fh8-HIC methodology The Fh8GFP purified protein from HIC/IMAC presented also high RFU values. The several GFP target proteins did also exhibit green light under natural daylight. Photos of all purified GFP proteins are available at the Supplementary file 4. 


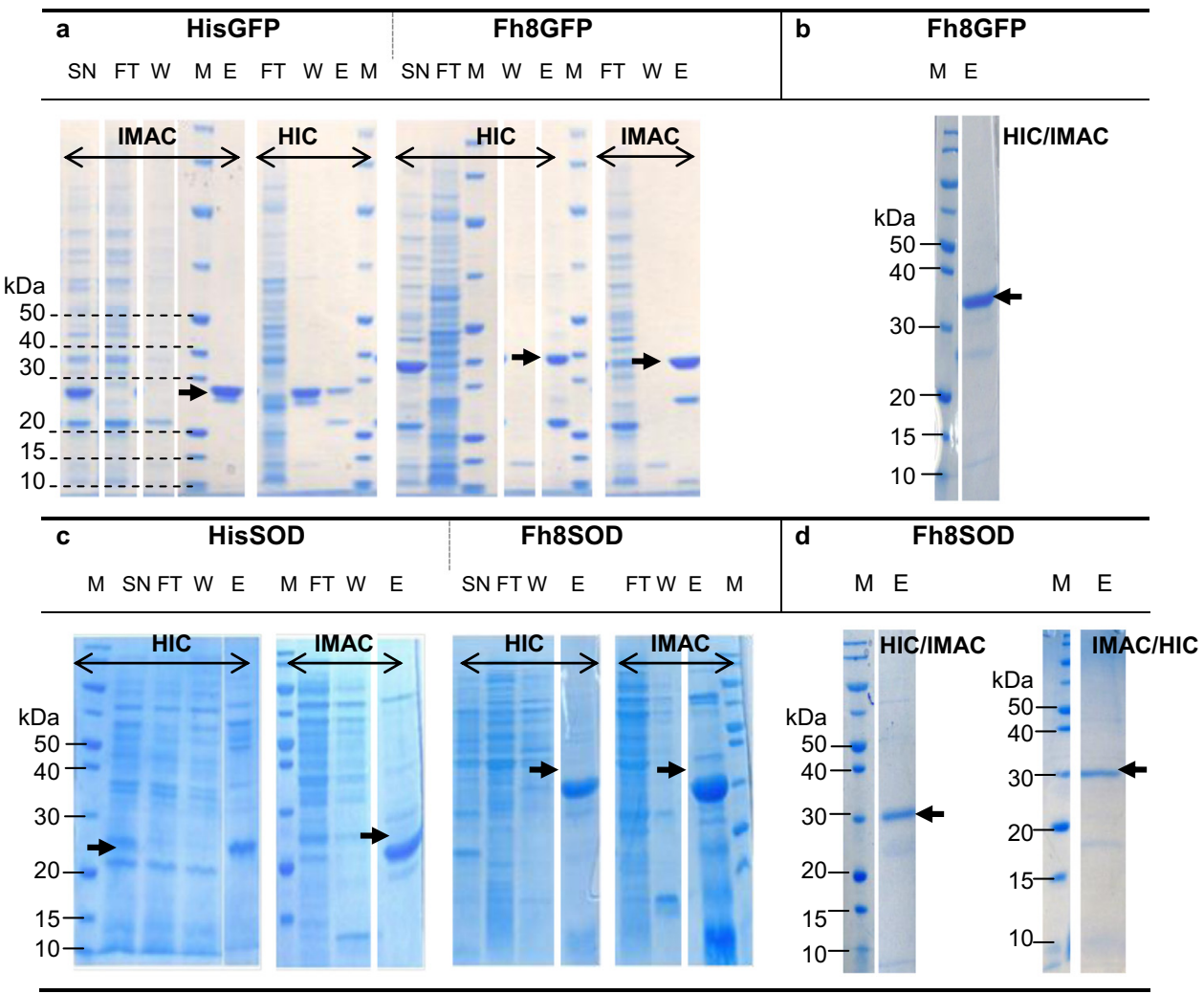

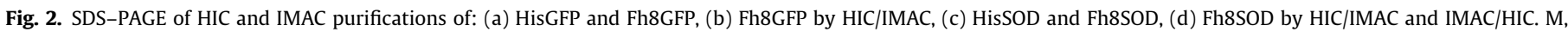

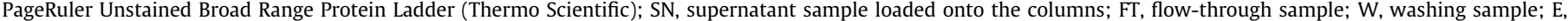

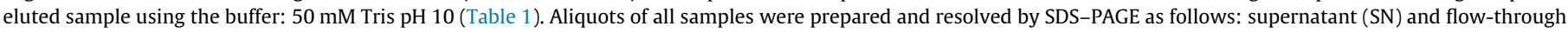

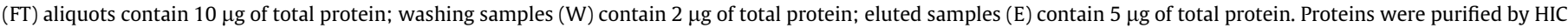
or IMAC using the buffers presented at Table 1. Arrows indicate the position of each recombinant protein in SDS-PAGE.

Table 3

Summary of Fh8 and His fusion protein purifications results by HIC and IMAC.

\begin{tabular}{|c|c|c|c|c|c|c|c|c|}
\hline & \multicolumn{2}{|l|}{ Fh8-GFP } & \multicolumn{2}{|l|}{ His-GFP } & \multicolumn{2}{|l|}{ Fh8-SOD } & \multicolumn{2}{|l|}{ His-SOD } \\
\hline & IMAC & HIC & IMAC & HIC & IMAC & HIC & IMAC & HIC \\
\hline Loaded $(\mathrm{mg})^{\mathrm{a}}$ & $55 \pm 2.1$ & $69 \pm 5.2$ & $48 \pm 2.5$ & $58 \pm 4.0$ & $7.9 \pm 0.014$ & $19 \pm 1.2$ & $9.7 \pm 0.56$ & $8.8 \pm 0.37$ \\
\hline Eluted $(\mathrm{mg})^{\mathrm{a}}$ & $40 \pm 2.2$ & $54 \pm 8.4$ & $30 \pm 3.3$ & $23 \pm 1.4$ & $5.5 \pm 0.18$ & $14 \pm 1.2$ & $5.0 \pm 0.30$ & 0 \\
\hline Yield (mg per g of E. coli dry weight) $)^{\mathrm{b}}$ & $61 \pm 3.4$ & $82 \pm 13$ & $46 \pm 5.1$ & $35 \pm 2.1$ & $14 \pm 0.45$ & $36 \pm 3.0$ & $19 \pm 1.1$ & 0 \\
\hline Purification efficiency $(\%)^{c}$ & $72 \pm 4.0$ & $77 \pm 12$ & $63 \pm 7.0$ & $39 \pm 2.0$ & $70 \pm 2.3$ & $75 \pm 6.3$ & $52 \pm 3.1$ & 0 \\
\hline
\end{tabular}

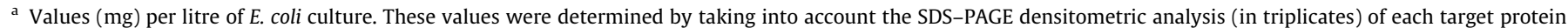
and the total protein amount presented in the loading or elution step, respectively.

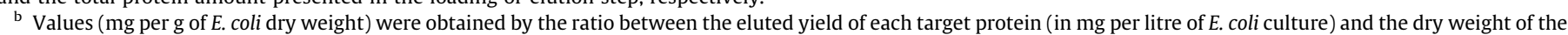
corresponding E. coli culture (in $\mathrm{g} / \mathrm{L}$ ). These values are calculated by the SDS-PAGE densitometric analysis for each target protein.

c Efficiency is the ratio between the target protein amount in the elution step ("Eluted") and the initially loaded amount of each target protein ("Loaded").

The Fh8SOD fusion protein purified by the Fh8-HIC strategy presented similar biological activity as the HisSOD protein purified by IMAC, and higher biological activity than the Fh8SOD purified by IMAC. In good agreement with the results observed for the GFP activity, the Fh8 tag did not also affect the SOD activity as fusion protein. The eluted sample from HisSOD purification by HIC did not present SOD activity, resulting in similar values as the Fh8GFP negative control protein. Taking into account this low activity and the SDS-PAGE analysis of Fig. 2, we confirmed that this eluted protein did not correspond to the HisSOD.

\section{Discussion}

In this study, a novel methodology for protein purification using the Fh8 solubility enhancer tag [21] was investigated. The chro- matographic properties of the Fh8 tag were firstly demonstrated through simple proof-of-principle experiments and the usefulness of the Fh8 as purification tag was then evaluated by its fusion to two different model proteins: GFP and SOD. The purification efficiency of Fh8-fused proteins by HIC was also compared to the His tag technology.

Taking into account the calcium binding property of Fh8 molecule [20] and its efficiency as solubility enhancer tag [21], the Fh8 was explored as a purification handle using a simple methodology: the hydrophobic interaction chromatography. Experiments using the Fh8 tag by itself demonstrated the calcium-dependent specificity of the binding mechanism and its affinity to the phenyl-Sepharose hydrophobic resin. In fact, the Fh8 could only bind the hydrophobic matrix in the presence of calcium in the mobile phase. Without calcium, the Fh8 tag presented low affinity for the matrix. The Fh8 tag was also able to bind to the phenyl-Sepharose resin 


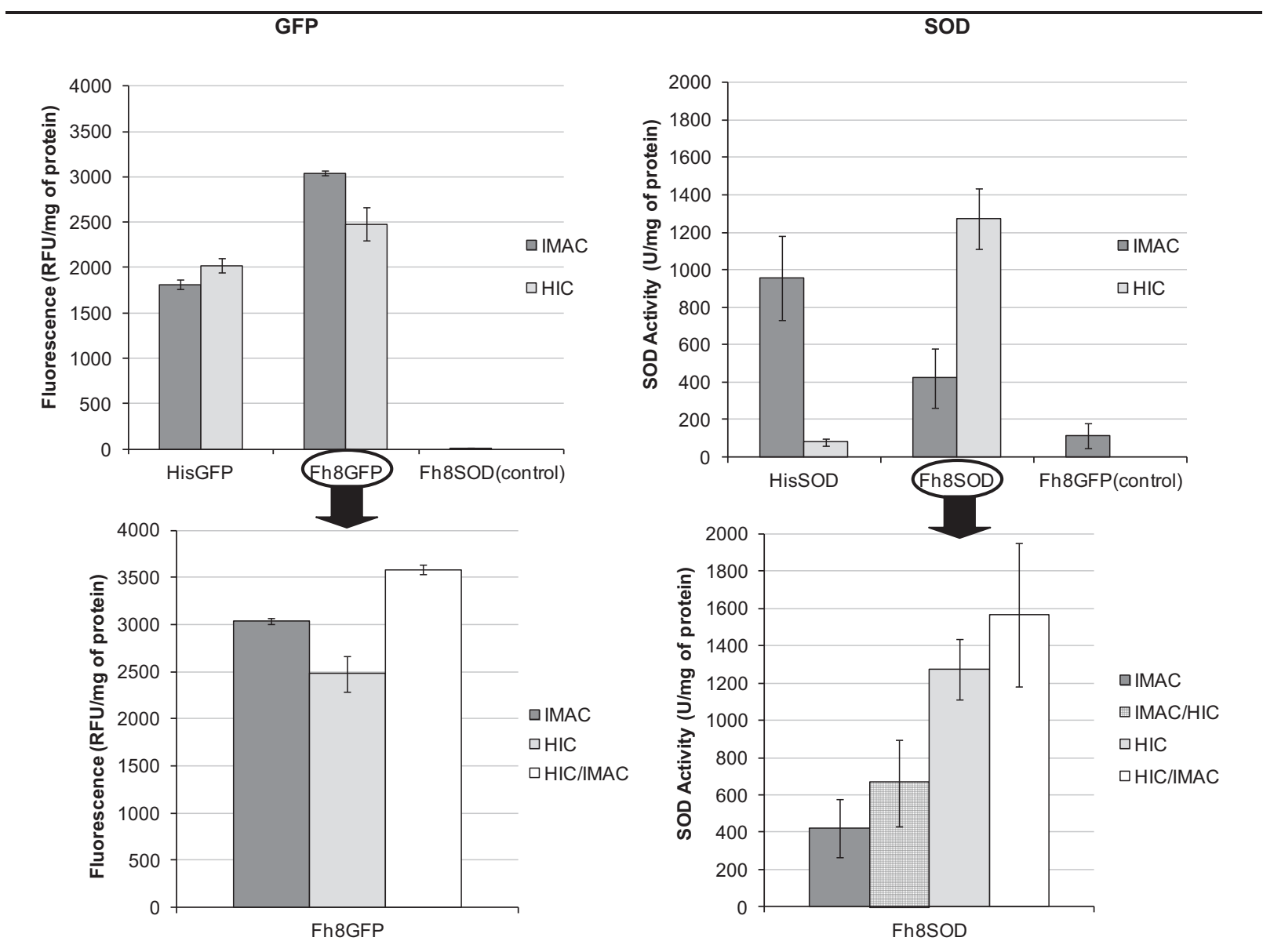

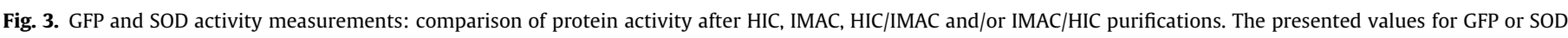

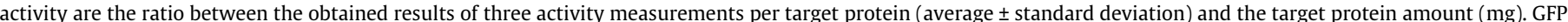

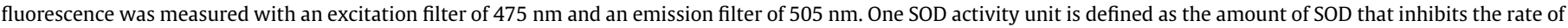
pyrogallol autoxidation by half at $\mathrm{pH} 8.2$ and $25^{\circ} \mathrm{C}$ ([27]).

under low salt concentration in the mobile phase, corroborating the results obtained for other calcium binding proteins [22,23]. The salt concentration in the mobile phase has significant contribution for the HIC performance: when using anti-chaotropic salts as sodium chloride, in a medium of high salt concentration, the bound form of the protein is thermodynamically more favorable than the unbound state. These salts bind water molecules strongly, excluding them from the protein and ligand surfaces, which start to interact hydrophobically (salting-out effect) [28-30]. Therefore, when using low salt concentrations in the mobile phase, the binding of proteins to the HIC matrix is not favored. Considering that the purification buffers used in this work have low salt concentrations, most of the contaminant proteins in the E. coli extract are excluded in the binding step, promoting selectivity towards the purification of the desired fusion protein. The Fh8 tag eluted from the phenyl-Sepharose column either with EDTA, or with $\mathrm{pH} 10$. The later was selected to perform the purification of Fh8 fusion proteins as it allowed a single-step and rapid elution of all bound proteins. The use of a calcium chelating agent has already been demonstrated to be effective for the elution of other calcium binding proteins [17,22,23]. In fact, this elution mechanism proved to be highly selective towards Fh8 tag since other proteins of superior molecular weight (between 20-25 and 50-75 kDa) were only observed in the elution with $\mathrm{pH}$ 10, after the first elution with EDTA. Overall, the Fh8 tag interacts with the HIC resin as a calcium binding protein and it has the properties required for protein purification by HIC, offering the possibil- ity to control the binding, selectivity and elution steps with the exclusion of major $E$. coli contaminants.

In order to investigate if the Fh8 tag could be used as a purification handle, namely, if chromatographic properties of Fh8 were preserved after fusion to target proteins, we selected two model target proteins with different characteristics, GFP and SOD. These proteins were fused to the Fh8 tag and to the $\mathrm{His}_{6}$ tag, and a Fh8-HIC purification protocol with mild conditions that did not interfere with target biological activity of target proteins was developed. Results from this work demonstrated that both Fh8GFP and Fh8SOD fusion proteins were soluble expressed in E. coli, and their purification efficiencies and biological activities after Fh8-HIC purification were comparable to those of Fh8-fused and His-fused proteins after IMAC purification. The higher biological activity observed for the Fh8SOD fusion protein purified by HIC or by HIC/IMAC may be explained by the calcium addition during the HIC purification protocol and its effect on SOD activity itself. Actually, the addition of calcium has a positive effect on SOD activity [31]. In order to corroborate this effect, we also compared the biological activity of Fh8SOD protein purified by IMAC with or without the addition of $\mathrm{CaCl}_{2} 5 \mathrm{mM}$, and an increase in SOD activity per $\mathrm{mg}$ of protein was observed (data not shown).

The HIC purification of both GFP and SOD proteins was only possible when fused to Fh8 tag as shown by the weak interaction of the $\mathrm{His}_{6}$-tagged proteins with the HIC matrix. This unfavorable interaction of HisGFP and HisSOD to the HIC matrix can be 
explained by the previously-mentioned low salt concentration used in the binding buffer. The difference between the $\mathrm{pH}$ value used in both binding and washing buffers ( $\mathrm{pH} 7.6)$ and the $\mathrm{pI}$ values of target proteins (5.8 for HisGFP and 5.9 for HisSOD) is probably causing a net charge shield around these proteins that will also decrease the chance for hydrophobic interactions [30,32].

The use of dual tags for expression and purification of recombinant proteins has become an increasingly popular method that simplifies purification and yields homogeneous preparations of the protein of interest [33]. Our results showed that the dual Fh8-HIC and IMAC purification system is an added-value strategy that can be used sequentially, complementing each other, to obtain an active and more purified protein when desired. Moreover, the use of two consecutive purification steps and the distinct nature of HIC and IMAC methodologies allows for the efficient removal of contaminating proteins [17].

The data presented here have proven the feasibility of the Fh8HIC purification strategy as a rapid, easy and cost-effective affinity methodology for protein recovery from E. coli extracts, even without an optimized purification protocol. Naturally, the Fh8-HIC methodology can be further optimized, as for instance, by testing other buffer solutions, hydrophobic matrices and EDTA/EGTA elution gradients, in order to use the Fh8 purification tag in a broader range of conditions.

The novel Fh8 purification tag presents attractive features when compared to other commonly affinity fusion technologies (see Table 4), being its efficient dual solubility enhancer and purification handle functionality the most relevant one. In fact, the Fh8 tag is one of the few existent fusion tags to combine both protein solubility enhancer and purification effects, along with the MBP and GST tags (Table 4). The MBP tag is a well-known solubility enhancer partner, but it presents some problems in protein interaction with the resin when used as a purification handle [34]. The GST tag is often described as a poor solubility enhancer $[21,35]$. Moreover, both fusion tags are large-sized tags, and require specific and expensive resins for protein purification. The Fh8 tag differs from MBP and GST traditional purification tags as it makes use of intrinsic calcium-binding properties for an economical hydrophobic interaction chromatography under mild conditions, instead of expensive resins, harsh buffers and additional compounds and ligands. The Fh8 tag goes forward the existing fusion tags by accumulating an efficient solubility enhancer activity and simple and cost-effective purification in a low molecular weight peptide.

The Fh8-HIC purification strategy is calcium-dependent and, consequently, chelating agents must be avoided during protein binding and washing steps. This could be considered a limitation of the process but it is important to mention that this limitation can also be found in the IMAC technology. Due to the calciumdependent mechanism for protein purification using the Fh8 tag, this Fh8-HIC strategy can be potentially applied for several different target proteins without requiring the development and optimization of a new system for each target protein.

\section{Conclusion}

The Fh8 solubility tag was successfully established in this work as an efficient purification handle, thus becoming one of the few existent fusion partners to combine an effective solubility enhancer activity and protein isolation in a single tag. Moreover, the Fh8 tag offers several benefits over other solubility and purification tags: a low molecular weight tag that may not disturb the biological activity of target proteins (as demonstrated in this study with two model proteins), a highly soluble and easy target protein production in E. coli, besides simplicity and economy of the entire protein's production process. Namely, it promotes target protein solubility directly into the E. coli cytoplasm and it does not require specialized buffers and substrates for protein purification, also making use of inexpensive and high-capacity matrices.

We foresee the novel Fh8 tag as a robust fusion partner of most utility for the rapid and cost-effective large scale soluble production and purification of several proteins. When desired, the Fh8 tag can also be used in a two-step purification procedure together

Table 4

Comparison of Fh8 fusion partner to other commonly used affinity partners.

\begin{tabular}{|c|c|c|c|c|c|}
\hline Tag & $\begin{array}{l}\text { Size } \\
\text { (aa) }\end{array}$ & Function & Purification protocol & Advantages & Disadvantages \\
\hline $\begin{array}{l}\text { Fh8 (Costa et al. [21], } \\
\text { and this work) }\end{array}$ & 69 & $\begin{array}{l}\text { SE } \\
\mathrm{PH}\end{array}$ & $\begin{array}{l}\text { Calcium dependent hydrophobic } \\
\text { interaction; selective elution } \\
\text { with EDTA or } \mathrm{pH} \text { manipulation }\end{array}$ & $\begin{array}{l}\text { Efficiently enhances protein solubility in } E \text {. coli; } \\
\text { small-sized tag; simple and cost-effective } \\
\text { purification using gentle and mild conditions }\end{array}$ & Possible oligomer formation \\
\hline MBP (Di Guan et al. [7]) & 396 & $\begin{array}{l}\text { SE } \\
\mathrm{PH}\end{array}$ & $\begin{array}{l}\text { Affinity towards amylose; } \\
\text { elution with maltose }\end{array}$ & $\begin{array}{l}\text { Enhances protein solubility in E. coli; simple } \\
\text { purification process }\end{array}$ & $\begin{array}{l}\text { Large tag; expensive process; problems in } \\
\text { protein interaction with the resin }\end{array}$ \\
\hline GST (Smith [6]) & 211 & $\begin{array}{l}\mathrm{SE} \\
\mathrm{PH}\end{array}$ & $\begin{array}{l}\text { Affinity towards glutathione, } \\
\text { elution with free glutathione }\end{array}$ & Simple purification process & $\begin{array}{l}\text { Poor solubility enhancer; large tag; } \\
\text { expensive process; problems in protein } \\
\text { interaction with the resin }\end{array}$ \\
\hline $\begin{array}{l}\text { Histidine (Hochuli et al. } \\
\text { [8]) }\end{array}$ & $\begin{array}{l}6- \\
10\end{array}$ & $\mathrm{PH}$ & $\begin{array}{l}\text { Affinity towards } \mathrm{Ni}^{2+} \text {; elution } \\
\text { with immidazole }\end{array}$ & Small-sized tag; simple purification process & $\begin{array}{l}\text { Purification efficiency can be reduced; } \\
\text { expensive process }\end{array}$ \\
\hline Si-tag (Ikeda et al. [10]) & 273 & & $\begin{array}{l}\text { Affinity towards sillica particles; } \\
\text { elution with high concentration } \\
\text { of } \mathrm{MgCl}_{2} \text { or } \mathrm{CaCl}_{2}\end{array}$ & $\begin{array}{l}\text { Inexpensive commercial silica particles; simple } \\
\text { purification process }\end{array}$ & $\begin{array}{l}\text { Requires detergents to minimize adsorption } \\
\text { of host proteins to the particles; high salt } \\
\text { concentration for elution; large size }\end{array}$ \\
\hline $\begin{array}{l}\text { Tamavidin (Takakura } \\
\quad \text { et al. [11]) }\end{array}$ & 140 & $\mathrm{PH}$ & $\begin{array}{l}\text { Affinity towards biotinylated } \\
\text { magnetic microbeads }\end{array}$ & High affinity protein immobilization & Expensive process; difficult elution ${ }^{a}$ \\
\hline $\begin{array}{l}\text { Tab2 tag (Crusius et al. } \\
\text { [12]) }\end{array}$ & 7 & $\begin{array}{l}\text { D } \\
\mathrm{PH}\end{array}$ & $\begin{array}{l}\text { Antibody-mediated protein } \\
\text { identification and purification; } \\
\text { elution at acidic } \mathrm{pH}(2.3)\end{array}$ & Specificity of binding & $\begin{array}{l}\text { Expensive process; harsh conditions for } \\
\text { elution }\end{array}$ \\
\hline $\begin{array}{l}\text { Z-basic (Hedhammar } \\
\text { and Hober [15]) }\end{array}$ & 58 & $\begin{array}{l}\mathrm{PH} \\
\mathrm{SE}\end{array}$ & $\begin{array}{l}\text { Cation-exchange } \\
\text { chromatography }\end{array}$ & $\begin{array}{l}\text { Simple and cost-effective purification process; } \\
\text { suitable for processes under denaturing } \\
\text { conditions }\end{array}$ & Poor solubility enhancer \\
\hline $\begin{array}{l}\text { Dock tag (Kamezaki } \\
\quad \text { et al. [16]) }\end{array}$ & 22 & $\mathrm{PH}$ & $\begin{array}{l}\text { Dockerin-cohesin calcium } \\
\text { dependent affinity }\end{array}$ & Highly selective & Expensive process \\
\hline $\begin{array}{l}\text { HiCaM (McCluskey } \\
\text { et al. [17]) }\end{array}$ & 162 & $\mathrm{PH}$ & Tandem IMAC-HIC purification & High purity level & Two-step process \\
\hline
\end{tabular}

Aa, amino acids; SE, solubility enhancer; PH, purification handle; D, detection; Q, quantification.

a Elution was carried by heating beads at $99^{\circ} \mathrm{C}$. 
with IMAC methodology, as well as other purification strategy, to further improve the protein purity level.

\section{Conflicts of interest}

The Fh8 tag utilization for the improvement of protein soluble expression in E. coli is covered by a worldwide patent (WO 2010082097) licensed to Hitag Biotechnology, Lda. The authors S.C., A.A. and A.C. are co-owners of the patent and are associated with Hitag Biotechnology, Lda.

\section{Contributors}

SC and EC participated in the study design and process development, carried out the experimental work and drafted the manuscript. LF participated in the experimental work and AA participated in results discussion and helped to draft the manuscript. LD and AC conceived and supervised the study, participated in its coordination and helped to draft the manuscript. All authors read and approved the final manuscript.

\section{Acknowledgments}

This work was conducted with the financial support of the Fundação para a Ciência e Tecnologia (FCT), Portugal, by the fellowship SFRH/BD/46482/2008 (POPH-QREN) to Sofia J. Costa. The FCT project PTDC/CVT/103081/2008 (co-funded by COMPETE) and QREN co-promotion project number 3515 are also acknowledged. The authors thank Dr. Hüseyin Besir, Protein Expression and Purification Facility Core, European Molecular Biology Laboratory (EMBL), Heidelberg, Germany, for supplying the pETM11 expression vector, and also Dr. Vítor Costa for kindly providing the SOD target gene used in this work.

\section{Appendix A. Supplementary data}

Supplementary data associated with this article can be found, in the online version, at http://dx.doi.org/10.1016/j.pep.2013.09.013.

\section{References}

[1] D. Esposito, D.K. Chatterjee, Enhancement of soluble protein expression through the use of fusion tags, Current Opinion in Biotechnology 17 (2006) 353-358.

[2] M.T.W. Hearn, D. Acosta, Applications of novel affinity cassette methods: use of peptide fusion handles for the purification of recombinant proteins, Journal of Molecular Recognition 14 (2001) 323-369.

[3] A. Malhotra, Tagging for Protein Expression, Methods in Enzymology, Elsevier Inc., 2009.

[4] E. Vernet, A. Kotzsch, B. Voldborg, M. Sundstrom, Screening of genetic parameters for soluble protein expression in Escherichia coli, Protein Expression and Purification 77 (2011) 104-111.

[5] D.S. Waugh, Making the most of affinity tags, Trends in Biotechnology 23 (2005) 316-320.

[6] D.B. Smith, K.S. Johnson, Single-step purification of polypeptides expressed in Escherichia coli as fusions with glutathione S-transferase, Gene 67 (1988) 3140.

[7] C. Di Guan, P. Li, P.D. Riggs, H. Inouye, Vectors that facilitate the expression and purification of foreign peptides in Escherichia coli by fusion to maltose-binding protein, Gene 15 (67) (1988) 21-30.

[8] E. Hochuli, H. Dobeli, A. Schacher, New metal chelate adsorbent selective for proteins and peptides containing neighboring histidine-residues, Journal of Chromatography 411 (1987) 177-184.

[9] J. Arnau, C. Lauritzen, G.E. Petersen, J. Pedersen, Current strategies for the use of affinity tags and tag removal for the purification of recombinant proteins, Protein Expression and Purification 48 (2006) 1-13.
[10] T. Ikeda, K. Ninomiya, R. Hirota, A. Kuroda, Single-step affinity purification of recombinant proteins using the silica-binding Si-tag as a fusion partner, Protein Expression and Purification 71 (2010) 91-95.

[11] Y. Takakura, N. Oka, H. Kajiwara, M. Tsunashima, S. Usami, H. Tsukamoto, Y. Ishida, T. Yamamoto, Tamavidin, a versatile affinity tag for protein purification and immobilization, Journal of Biotechnology 145 (2010) 317-322.

[12] K. Crusius, S. Finster, J. McClary, W. Xia, B. Larsen, D. Schneider, H.T. Lu, S Biancalana, J.A. Xuan, A. Newton, D. Allen, P. Bringmann, R.R. Cobb, Tab2, a novel recombinant polypeptide tag offering sensitive and specific protein detection and reliable affinity purification, Gene 380 (2006) 111-119.

[13] L. Wang, J.H. Kang, K.H. Kim, E.K. Lee, Expression of intein-tagged fusion protein and its applications in downstream processing, Journal of Chemical Technology and Biotechnology 85 (2010) 11-18.

[14] W.B. Asher, K.L. Bren, A heme fusion tag for protein affinity purification and quantification, Protein Science 19 (2010) 1830-1839.

[15] M. Hedhammar, S. Hober, Z(basic) - A novel purification tag for efficient protein recovery, Journal of Chromatography A 1161 (2007) 22-28.

[16] Y. Kamezaki, C. Enomoto, Y. Ishikawa, T. Koyama, S. Naya, T. Suzuki, K. Sakka, The Dock tag, an affinity tool for the purification of recombinant proteins, based on the interaction between dockerin and cohesin domains from Clostridium josui cellulosome, Protein Expression and Purification 70 (2010) 23-31.

[17] A.J. McCluskey, G.M.K. Poon, J. Gariepy, A rapid and universal tandempurification strategy for recombinant proteins, Protein Science 16 (2007) 2726-2732.

[18] J.J. Lichty, J.L. Malecki, H.D. Agnew, D.J. Michelson-Horowitz, S. Tan, Comparison of affinity tags for protein purification, Protein Expression and Purification 41 (2005) 98-105.

[19] E. Silva, A. Castro, A. Lopes, A. Rodrigues, C. Dias, A. Conceicao, J. Alonso, J.M.C. da Costa, M. Bastos, F. Parra, P. Moradas-Ferreira, M. Silva, A recombinant antigen recognized by Fasciola hepatica-infected hosts, Journal of Parasitology 90 (2004) 746-751.

[20] H. Fraga, T.Q. Faria, F. Pinto, A. Almeida, R.M.M. Brito, A.M. Damas, FH8-a small EF-hand protein from Fasciola hepatica, FEBS Journal 277 (2010) 5072-5085.

[21] S.J. Costa, A. Almeida, A. Castro, L. Domingues, H. Besir, The novel Fh8 and H fusion partners for soluble protein expression in Escherichia coli: a comparison with the traditional gene fusion technology, Applied Microbiology and Biotechnology 97 (2013) 6779-6791.

[22] C. Rozanas, Purification of calcium-binding proteins using hydrophobic interaction chromatography, Life Science News I (1998) 1-14.

[23] F. Shimizu, K. Sanada, Y. Fukada, Purification and immunohistochemical analysis of calcium-binding proteins expressed in the chick pineal gland, Journal of Pineal Research 34 (2003) 208-216.

[24] U.K. Laemmli, Cleavage of structural proteins during assembly of head of bacteriophage-T4, Nature 227 (1970) 680.

[25] H. Schagger, G. von Jagow, Tricine-sodium dodecyl sulfate-polyacrylamide ge electrophoresis for the separation of proteins in the range from 1 to $100 \mathrm{kDa}$, Analytical Biochemistry 166 (1987) 368-379.

[26] M.M. Bradford, A rapid and sensitive method for the quantitation of microgram quantities of protein utilizing the principle of protein-dye binding, Analytical Biochemistry 72 (1976) 248-254.

[27] S. Marklund, G. Marklund, Involvement of superoxide anion radical in autoxidation of pyrogallol and a convenient assay for superoxide-dismutase European Journal of Biochemistry 47 (1974) 469-474.

[28] M.E. Lienqueo, A. Mahn, J.C. Salgado, J.A. Asenjo, Current insights on protein behaviour in hydrophobic interaction chromatography, Journal of Chromatography B-Analytical Technologies in the Biomedical and Life Sciences 849 (2007) 53-68.

[29] J.A. Queiroz, C.T. Tomaz, J.M.S. Cabral, Hydrophobic interaction chromatography of proteins, Journal of Biotechnology 87 (2001) 143-159.

[30] K. Tsumoto, D. Ejima, A.M. Senczuk, Y. Kita, T. Arakawa, Effects of salts on protein-surface interactions: applications for column chromatography, Journal of Pharmaceutical Sciences 96 (2007) 1677-1690.

[31] N.T. Bakardjieva, K.N. Christov, N.V. Christova, Effect of calcium and zinc on the activity and thermostability of superoxide dismutase, Biologia Plantarum 43 (2000) 73-78.

[32] F. Xia, D. Nagrath, S.M. Cramer, Effect of pH changes on water release values in hydrophobic interaction chromatographic systems, Journal of Chromatography A 1079 (2005) 229-235.

[33] K. Terpe, Overview of tag protein fusions: from molecular and biochemical fundamentals to commercial systems, Applied Microbiology and Biotechnology 60 (2003) 523-533.

[34] K.D. Pryor, B. Leiting, High-level expression of soluble protein in Escherichic coli using a His(6)-tag and maltose-binding-protein double-affinity fusion system, Protein Expression and Purification 10 (1997) 309-319.

[35] L.E. Bird, High throughput construction and small scale expression screening of multi-tag vectors in Escherichia coli, Methods 55 (2011) 29-37. 